\title{
Effects of asthma severity, exacerbations and oral corticosteroids on perinatal
}

\section{outcomes}

\author{
Jennifer A. Namazy*, Vanessa E. Murphy", Heather Powell ${ }^{\#, \mp}$, Peter G. Gibson\#, ${ }^{\#,}$ \\ Christina Chambers $^{+}$and Michael Schatz ${ }^{\S}$
}

ABSTRACT: This systematic review and meta-analysis sought to investigate whether asthma exacerbations, oral corticosteroid use or asthma severity are associated with prematurity and intrauterine growth restriction.

Cohort studies published between 1975 and March 11, 2012 were considered for inclusion. 138 publications were identified for possible inclusion, and nine papers met the inclusion criteria, by reporting perinatal outcomes of interest (low birth weight, $<2500 \mathrm{~g}$ ), pre-term birth ( $<37$ weeks gestation unless otherwise stated) and small for gestational age ( $<10$ th percentile for gestational age and sex) in groups of asthmatic patients stratified by history of exacerbations, oral corticosteroid use or asthma severity.

Maternal asthma exacerbations and oral corticosteroid use had a significant effect on outcomes, including low birth weight (RR 3.02, 95\% Cl 1.87-4.89 and RR 1.41, 95\% Cl 1.041.93, respectively) and pre-term delivery (RR 1.54, 95\% Cl 0.89-2.69 and RR 1.51, 95\% Cl 1.151.98, respectively). Moderate-to-severe asthma during pregnancy was associated with an increased risk of small for gestational age (RR 1.24, 95\% Cl 1.15-1.35) and low birth weight (RR 1.15, 95\% Cl 1.05-1.26) infants.

These data suggest that asthma exacerbations, oral corticosteroid use or asthma severity defined as moderate-to-severe may be associated with pre-term delivery, low birth weight, and small for gestational age infants. Further studies on the effect of maternal asthma control on perinatal outcomes are warranted.

KEYWORDS: Asthma, low birth weight, oral corticosteroid, pregnancy, pre-term delivery, small for gestational age

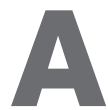
sthma is the most common medical condition to affect pregnancy, with a prevalence of $8-13 \%$ worldwide [1-3]. It has been suggested that asthma may have an effect on pregnancy outcomes, and also that pregnancy may affect the course of asthma [4], but the published data have been conflicting. For this reason we recently conducted a meta-analysis to investigate whether maternal asthma is associated with an increased risk of pregnancy and neonatal complications. We found that females with asthma during pregnancy are at an increased risk of perinatal complications including low birth weight, pre-term delivery and small for gestational age infants [5].

Approximately $70 \%$ of all low birth weight infants are a result of pre-term delivery before 37 completed weeks of pregnancy. Therefore, the observed increase in pre-term delivery in pregnant asthmatics may explain most of the increased prevalence of low birth weight in their infants. However, small for gestational age, most often a result of intrauterine growth restriction, may occur in either term or pre-term infants and also accounts for some low birth weight infants.

Mechanisms for these adverse perinatal outcomes have not been defined. Several studies have reported a relationship between increased asthma severity or decreased asthma control and increased risk of low birth weight, small for gestational age and pre-term delivery [6-18]. One recent meta-analysis found that pregnant asthmatic females with a history of severe exacerbation during pregnancy are at a significantly increased risk of perinatal complications including low birth weight [19]. The use of asthma medications such as oral corticosteroids (OCS) during pregnancy may also play a potential role
AFFILIATIONS

*Dept of Allergy-Immunology, Scripps Clinic, San Diego, CA, +Pediatrics and Family and Preventative Medicine, University of California, San Diego, CA, and ${ }^{\S}$ Dept of Allergy, Kaiser Permanente Medical Center, San Diego, CA, USA ${ }^{\#}$ Centre for Asthma and Respiratory Diseases, University of Newcastle and Hunter Medical Research Institute, Newcastle, and "John Hunter Hospital, Newcastle, Australia.

\section{CORRESPONDENCE}

J.A. Namazy

Scripps Clinic

7565 Mission Valley Road

San Diego

CA 92108

USA

E-mail: janamazy@mac.com

Received:

Nov 092011

Accepted after revision:

July 192012

First published online:

Aug 162012

European Respiratory Journal Print ISSN 0903-1936

Online ISSN 1399-3003 
TABLE 1 Definition of "severity" used in studies addressing the associations between asthma severity and perinatal outcomes

\begin{tabular}{|c|c|c|}
\hline First author [ref.] & Severity & Definition \\
\hline \multirow[t]{4}{*}{ DomBRowskı [13] } & Mild & Asthma symptoms in the previous 6 months \\
\hline & & FEV $1 \geqslant 80 \%$ pred \\
\hline & & Not taking daily asthma medication \\
\hline & Moderate/severe & $\begin{array}{l}\text { Asthma symptoms on } \geqslant 8 \text { days during the previous } 4 \text { weeks not attributable to a URI } \\
\text { FEV } 1<60-79 \% \text { pred }\end{array}$ \\
\hline \multirow[t]{2}{*}{ KaLLen [21] } & Mild & 1 asthma drug \\
\hline & Moderate/severe & $\geqslant 2$ asthma drugs \\
\hline \multirow[t]{4}{*}{ FIROOZI $[22,23]$} & Asthma severity index & \\
\hline & Mild & ICS 0-500 g.day ${ }^{-1}$ and no additional controller therapy or 0-250 $\mu \mathrm{g} \cdot$ day $^{-1}$ and additional controller therapy \\
\hline & & No more than three doses of SABA over a 12-month period \\
\hline & Severe & ICS $>1000 \mu \mathrm{g} \cdot$ day $^{-1}$ or $>10$ doses SABA per week and moderate-to-severe exacerbation \\
\hline
\end{tabular}

FEV1: forced expiratory volume in $1 \mathrm{~s}$; \% pred: \% predicted; URI: upper respiratory infection; OCS: oral corticosteroids; ICS: inhaled corticosteroid; SABA: short-acting $\beta$-agonist.

in leading to pre-term delivery or low birth weight infants [20] and have been suggested as contributing factors by several large cohort studies $[9,13]$.

To better understand potential mechanisms involved in the increased risk of prematurity and intrauterine growth restriction observed in mothers with asthma we have undertaken a systematic review of the literature and meta-analyses to investigate whether maternal asthma severity, history of exacerbation or OCS use during pregnancy are associated with the risk of pre-term, low birth weight or small for gestational age infants.

\section{METHODS}

\section{Systematic review of the literature: search strategy}

English language studies published between January 1975 (when inhaled corticosteroids were introduced) and March 2012 were identified for possible inclusion from MEDLINE $(n=1642)$, EMBASE $(n=1755)$, Cumulative Index to Nursing and Health Literature (CINAHL) $(\mathrm{n}=417)$ and Cochrane Central Register of Controlled Trials $(n=75)$, using search terms ((asthma or wheeze) and (pregnan* or perinat* or obstet*)). An update was conducted and the search for the update was January 2009 to March 2012 to ensure that no articles were missed. The numbers for the update were: MEDLINE $(n=681)$, EMBASE $(n=624)$, CINAHL $(n=84)$ and Cochrane Central Register of Controlled Trials $(n=14)$. All identified abstracts were independently assessed by two reviewers. The full-text version of each potential article was obtained for assessment by two independent reviewers to establish whether it met the inclusion criteria.

\section{Inclusion criteria}

Articles were included if they were cohort studies that contained data comparing perinatal outcomes of interest (see below) in groups of asthmatic patients stratified by history of exacerbations, OCS use or asthma severity. Asthma was defined as physician-diagnosed asthma (whether confirmed or subject self-reported), or an asthma diagnosis as coded in a database or asthma fulfilling American Thoracic Society criteria. Females with asthma were further classified by symptom severity according to national and international guidelines (Global Initiative for Asthma or National Asthma Education Program Working Group on Asthma and Pregnancy) [13], number of medications used to control asthma symptoms (one drug: mild; two and three drugs: moderate/severe) [21] or a validated index combining medication use and markers of exacerbation (table 1) $[22,23]$. Exacerbations of asthma were defined (table 2) as symptoms requiring medical interventions such as hospitalisation, emergency department visits, other unscheduled urgent visits to the doctor or the use of emergency treatment. In two of the studies, emergency treatment included the use of OCS [7, 24]. Most studies included exacerbations occurring any time during pregnancy, with the exception of one study which limited exacerbations to the first trimester only [13]. Perinatal outcomes of interest for this article included low birth weight $(<2500 \mathrm{~g})$, pre-term birth $(<37$ weeks gestation unless otherwise stated), and small for gestational age $(<10$ th percentile for gestational age and sex).

\section{Description of studies}

138 publications were identified for possible inclusion in the review. Nine papers describing seven prospective and two retrospective cohort studies met the inclusion criteria (table 3). 129 papers were excluded for the following reasons: no asthma sub-groups $(n=29)$, poorly defined asthma sub-groups $(n=6)$, asthma sub-groups that did not meet our inclusion criteria 


\begin{tabular}{|c|c|}
\hline First author [ref.] & Definition of exacerbation \\
\hline MURPHY [7] & Hospital admission, emergency department presentation, unscheduled doctor's visit or course of OCS \\
\hline Stenius-Aarniala [6] & Not controlled by the patient's normal rescue medication and which was treated as an emergency $(74.4 \%$ OCS) \\
\hline JANA [12] & Requiring emergency services and/or hospitalisation \\
\hline GREENBERGER [16] & Requiring adrenaline and OCS in the outpatient service, emergency room or hospital \\
\hline
\end{tabular}

$(n=24)$, no asthma comparison group $(n=10)$, study published after 1975 but conducted prior to $1975(n=2)$, cross-sectional survey $(n=3)$, abstract only $(n=10)$, no perinatal outcomes reported $(n=16)$, review article $(n=6)$, case-control study design $(n=15)$, data presented as odds ratio only $(n=4)$, retracted article $(n=1)$ and overlapping data with another study $(n=3)$ (table 4$)$.

\section{Data extraction}

Data were extracted using a standardised form by one reviewer and checked by a second reviewer. Any discrepancies were discussed by the investigators in order to reach a consensus. Study authors were contacted to clarify an outcome definition where necessary.

Data were extracted for: study design; study characteristics (including year and country of study); subject characteristics (including gestational age at recruitment, subject exclusions, maternal age, body mass index, smoking, socioeconomic status, pre-natal care, race/ethnicity and comorbidities); asthma diagnosis; severity of asthma; medication management; exacerbations; and perinatal outcome for asthma subgroups (data mostly presented as $\mathrm{n}(\%)$ or mean $\pm \mathrm{SD}$ ).

Study quality was assessed independently and scored by two reviewers using the Newcastle-Ottawa Scale [89]. The NewcastleOttawa Scale is a validated tool for assessing the quality of nonrandomised studies, including cohort and case-control studies, and has a maximum score of 9 . The mean quality score of included studies (8.3) (table 3) was ranked as good.

\section{Meta-analysis}

The meta-analyses conformed to standard methodological guidelines for observational studies [90]. The relative risk of the perinatal outcome was examined in sub-groups of females with asthma stratified by severity (mild versus moderate-tosevere), gestational asthma exacerbations (expressed as a yes/ no variable) and exposure to OCS (expressed as a yes/no variable) using Review Manager software (RevMan 4.2.7, Wintertree Software Inc, Ontario, Canada). For dichotomous outcomes the relative risk (RR) and 95\% confidence interval were calculated using a fixed-effects model. Heterogeneity was examined using the Chi-squared test $(\mathrm{p}<0.1$ considered to show significant heterogeneity) and the $\mathrm{I}^{2}$ percentage $\left(\mathrm{I}^{2} \geqslant 60 \%\right.$ considered to show significant heterogeneity; RevMan, Wintertree Software Inc.).

\section{RESULTS}

\section{Relationship between asthma exacerbations and perinatal outcome}

Pre-term delivery

Data on pre-term delivery was reported in five prospective studies $[6,7,12,16,17]$ of 179 subjects experiencing exacerbations during pregnancy and 1035 subjects without exacerbations. The data from two papers from FITZSIMONS et al. [18] and GREENBERGER and PATterson [16] published in 1986 and 1988, respectively, were overlapping, and so the data from the 1988 paper, which contained a larger group of subjects, has been included here (and for subsequent analyses reported below) [16]. In the study by JANA et al. [12] there was a comparison of "mild versus severe asthma", which we translated to "no exacerbation versus exacerbation", since their definition of "severe" asthma was asthma which required emergency hospitalisation for symptoms. Overall, there was a nonsignificant trend of increased pre-term delivery in asthmatics with exacerbations during pregnancy (RR 1.54, 95\% CI $0.89-2.69)$. There was no significant heterogeneity among studies $\left(\mathrm{I}^{2}=0 \%, \mathrm{p}>0.1\right)$.

\section{Low birth weight}

Data on low birth weight were included in four prospective studies [7, 12, 16, 18] with 147 subjects with an exacerbation during pregnancy and 747 subjects without an exacerbation during pregnancy. There was a significantly increased risk of low birth weight infants in those subjects experiencing asthma exacerbation during pregnancy (RR 3.02, 95\% CI 1.87-4.89). There was no significant heterogeneity among studies $\left(\mathrm{I}^{2}=0 \%\right.$, $\mathrm{p}>0.1$ ) (fig. 1).

\section{Small for gestational age}

Data on small for gestational age infants were included in two studies [16, 17] with 80 subjects experiencing exacerbations during pregnancy and 487 subjects without exacerbations. There was no significant increased risk of small for gestational age infants in those asthmatics experiencing exacerbation during pregnancy compared to those with no severe exacerbations during pregnancy (RR 0.78, 95\% CI 0.25-2.48). However, significant heterogeneity was present $\left(\mathrm{I}^{2}=71.1 \%\right.$, $\mathrm{p}=0.06$ ). 


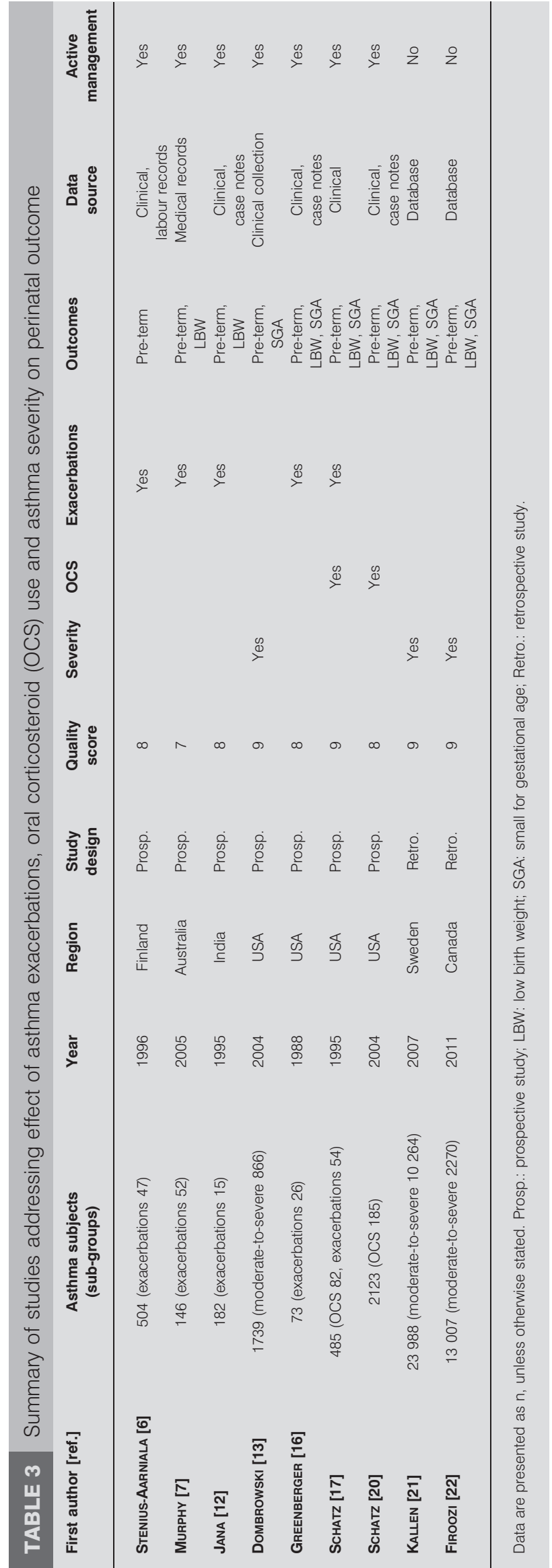

\section{Relationship between OCS use and perinatal outcome \\ Pre-term delivery}

Data on pre-term delivery was included in two prospective studies [17, 20] with 267 subjects who used OCS during pregnancy compared with 2341 subjects who did not use OCS during pregnancy. Overall, OCS use increased the relative risk of pre-term delivery (RR 1.51, 95\% CI 1.15-1.98), with no significant heterogeneity between studies $\left(\mathrm{I}^{2}=0 \%, \mathrm{p}>0.1\right)$ (fig. 2).

\section{Low birth weight}

Data on low birth weight was included in two prospective studies [17, 20] with 267 subjects who used OCS during pregnancy and 2341 subjects who did not use OCS. Overall, there was a significant increased risk of low birth weight infants to those females using OCS during pregnancy (RR 1.41, 95\% CI 1.04-1.93). There was no heterogeneity between studies (fig. 3).

\section{Small for gestational age}

There were two prospective studies [17, 20] of small for gestational age, with 267 subjects who used OCS during pregnancy and 2341 subjects who did not use OCS during pregnancy. Overall, there was no significant increased risk of small for gestational age among females using OCS during pregnancy (RR 0.81, 95\% CI 0.48-1.34).

\section{Relationship between asthma severity and perinatal outcomes}

\section{Pre-term delivery}

There were three studies reporting on the effect of maternal asthma severity on pre-term delivery [13, 21, 22]. One retrospective [21] and one prospective study [13] reported early pre-term delivery at $<32$ weeks of completed gestation as an outcome. Overall, the risk of early pre-term delivery was not increased in females with moderate-to-severe asthma compared with females with mild asthma (RR 1.08, 95\% CI 0.4-1.39).

Two retrospective [21, 22] and one prospective study [13] reported pre-term delivery at $<37$ weeks gestation. Overall, there was no increased risk of pre-term delivery in moderate-tosevere versus mild asthmatic females (RR 1.00, 95\% CI 0.93-1.09).

\section{Low birth weight}

Two retrospective studies [21, 22] reported low birth weight among females with mild and moderate-to-severe asthma. There was an increased risk of low birth weight in moderate-to-severe versus mild asthmatic females (RR 1.15, 95\% CI 1.05-1.26).

\section{Small for gestational age}

There were two retrospective studies [21, 22] and one prospective study [13] with 13400 subjects with moderate-tosevere asthma and 25334 subjects with mild asthma severity. Meta-analysis comparing mild to moderate-to-severe asthmatics demonstrated a significantly increased risk of small for gestational age in infants of subjects with asthma classified as moderate-to-severe compared with those with mild asthma during pregnancy (RR 1.24, 95\% CI 1.15-1.35). There was no significant heterogeneity between studies $\left(\mathrm{I}^{2}=20.9 \%, \mathrm{p}>0.1\right)$ (fig. 4). 


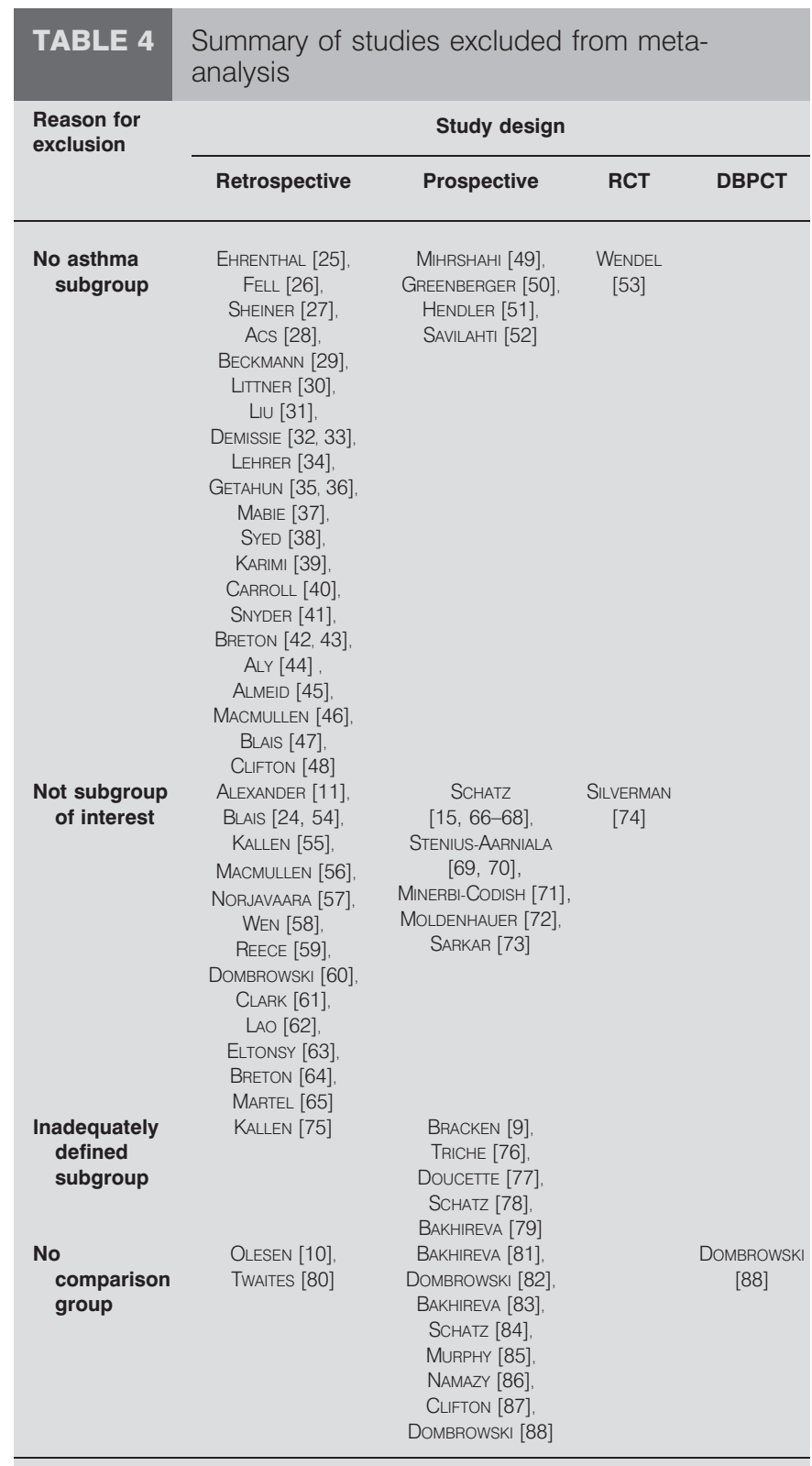

RCT: randomised controlled trial; DBPCT: double-blind placebo controlled trial.

\section{DISCUSSION}

Previous studies, as well as a recent meta-analysis [5], have shown that pregnancies in females with asthma when compared with pregnancies in non-asthmatic females are at an increased risk of pre-term birth, low birth weight and small for gestational age infants. Until now it has been unclear which mechanisms are responsible for these observations. Our results show that exacerbations and OCS use during pregnancy are associated with an increased incidence of pre-term and low birth weight infants, while moderate-to-severe asthma during pregnancy is associated with an increased risk of low birth weight and small for gestational age infants (table 5). These results suggest that acute asthma events (exacerbations and OCS use) increase the risk of prematurity, while greater severity increases the risk of intrauterine growth restriction.

A recent population-based cohort study published after the end of our meta-analysis inclusion period of $>40000$ pregnancies

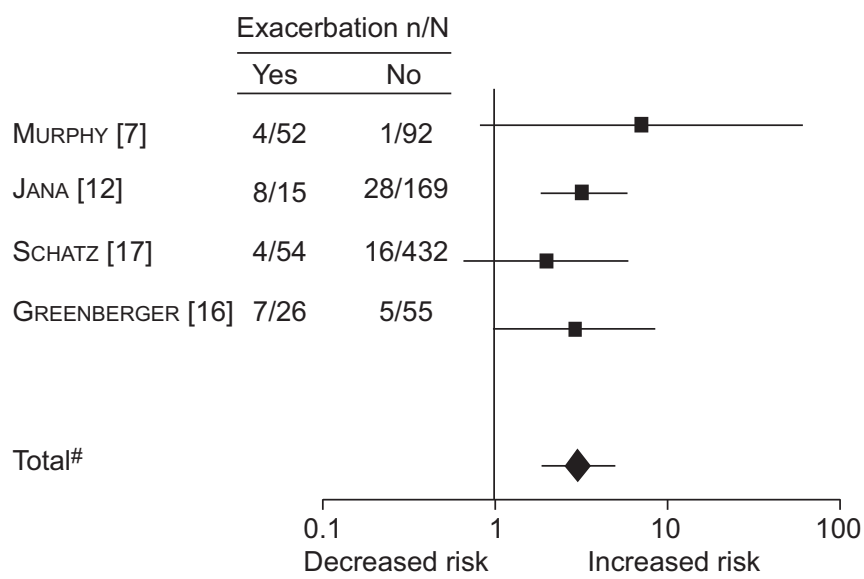

FIGURE 1. Meta-analysis of cohort studies for low birth weight. Increased risk indicates that the outcome was more likely in subjects with a history of asthma exacerbation during pregnancy. Data are presented as relative risk $(95 \% \mathrm{Cl})$. Heterogeneity: $p=0.75, I^{2}=0 \%$; effect: $p<0.00001$. * : RR 3.02 (95\% Cl 1.87-4.89).

found that asthmatic females with a history of exacerbation defined as acute care for asthma recorded in the databases were more likely to have a low birth weight or pre-term infant than non-asthmatic females [5], agreeing with the results of this metaanalysis. However, this study also found an increased risk of small for gestational age infants in asthmatic females with exacerbations compared with non-asthmatic females. This finding is at variance with our results, but may be related to the different comparison groups used in their study (nonasthmatic females) versus our meta-analysis (asthmatic females without exacerbations).

Another recent study of $>9000$ pregnant asthmatic females showed that those females with a hospitalisation or emergency department visit had an increased risk of low birth weight infants [91]. MURPHY et al. [19] reported in a meta-analysis of 855 asthmatics that there was an increased risk of low birth weight infants but not pre-term delivery associated with

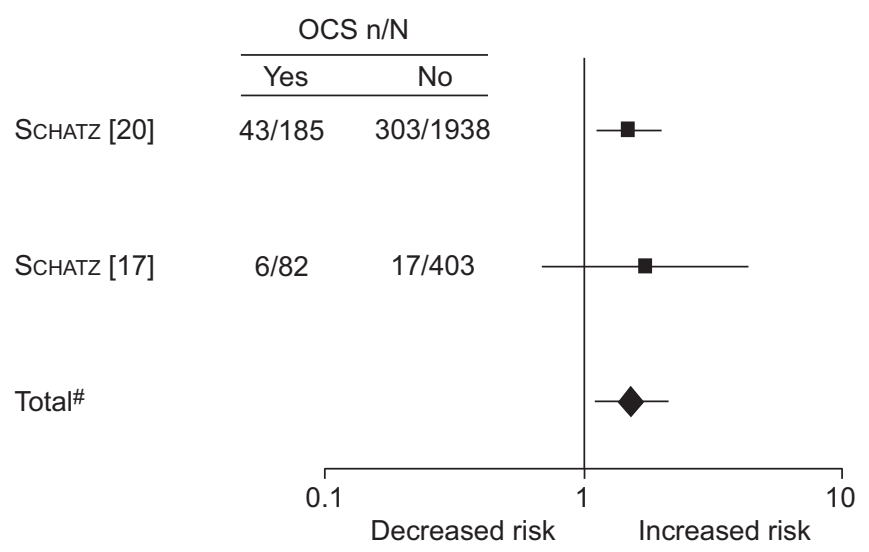

FIGURE 2. Meta-analysis of cohort studies for pre-term delivery. Increased risk indicates that the outcome was more likely in subjects with a history of oral corticosteroid (OCS) use during pregnancy. Data are presented as relative risk $(95 \% \mathrm{Cl})$. Heterogeneity: $p=0.75, \mathrm{I}^{2}=0 \%$; effect: $p=0.003 .{ }^{\#}$ : RR $1.51(95 \% \mathrm{Cl} 1.15-$ 1.98). 


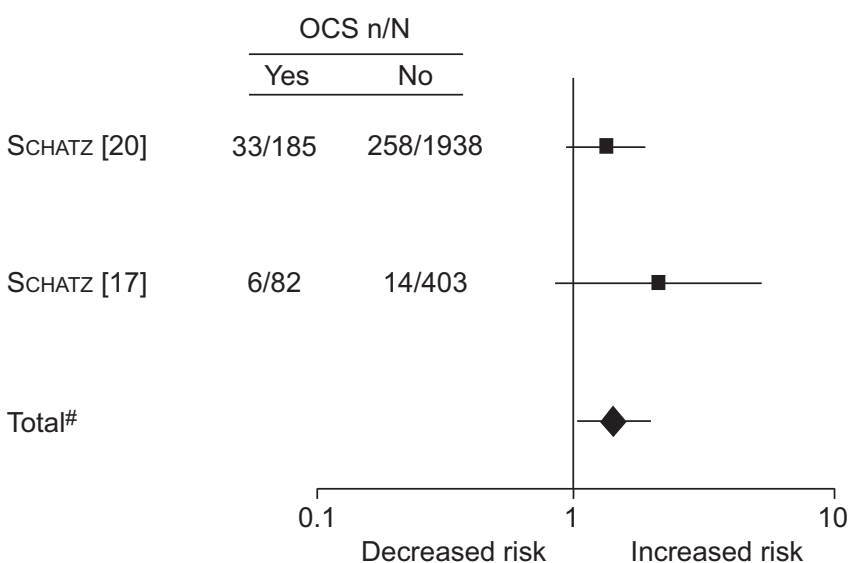

FIGURE 3. Meta-analysis of cohort studies for low birth weight. Increased risk indicates that the outcome was more likely in subjects with a history of oral corticosteroid (OCS) use during pregnancy. Data are presented as relative risk $(95 \% \mathrm{Cl})$. Heterogeneity: $\mathrm{p}=0.37, \mathrm{l}^{2}=0 \%$; effect: $\mathrm{p}=0.003$. ${ }^{*}$ : RR 1.41 (95\% Cl 1.041.93).

exacerbations during pregnancy. For our meta-analysis, the cause of asthma exacerbations was unknown in all studies except one [7], whose authors found that triggers included non-adherence to inhaled corticosteroid medications in about a third of patients and viral infection in another third. STENIUSAARNIALA et al. [6] found that 31 out of the 45 subjects with a history of exacerbation during pregnancy were not using inhaled corticosteroids. Two studies also examined potential maternal risk factors for asthma exacerbations, such as age, parity, smoking and body mass index, and found no significant differences between females who had a severe exacerbation and those who did not $[7,17]$. An interesting observation by GREENBERGER and PATTERSON [16] was that while subjects with untreated status asthmaticus had a higher risk of adverse perinatal outcomes, those subjects who were treated for exacerbations with inhaled corticosteroids or OCS had much more favourable outcomes. In our analysis, the relative risk of low birth weight in OCS users (RR 1.41) was approximately half that of females with severe exacerbations (RR 3.02). A possible mechanism for the effect of severe asthma or exacerbations on perinatal outcomes includes a direct effect of fetal hypoxia on fetal growth, or indirect effects of placental insufficiency [85], both of which could presumably be mitigated by prevention or possibly expeditious treatment of asthma exacerbations.

When we examined the potential effect of OCS use on perinatal outcomes, we found that pregnant asthmatic females who used

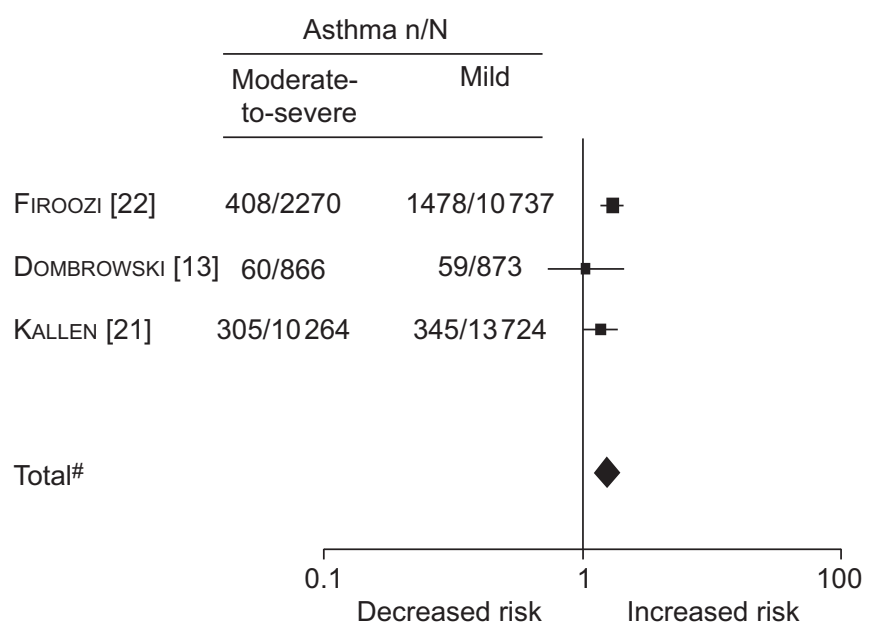

FIGURE 4. Meta-analysis of cohort studies for small for gestational age infants. Increased risk indicates that the outcome was more likely in subjects with a history of moderate-to-severe asthma during pregnancy. Data are presented as relative risk $(95 \% \mathrm{Cl})$. Heterogeneity: $p=0.28, \mathrm{l}^{2}=20.9 \%$; effect: $p=0.00001$. ${ }^{\#}: \mathrm{RR}$ 1.24 (95\% Cl 1.15-1.35).

OCS during pregnancy had an increased risk of pre-term delivery (<37 completed weeks gestation) and low birth weight infants. There have been several cohort studies that have shown significant effects of maternal asthma on pre-term delivery that may be related to OCS use. Pregnant asthmatics taking a mean daily dose of $8 \mathrm{mg}$ of prednisone a day had an increased risk of pre-term delivery [80]. DOMBROWSKI et al. [13] found a significant effect of severe asthma (forced expiratory volume in $1 \mathrm{~s}$ (FEV1) $<60 \%$ and/or OCS use in the 4 weeks prior to enrolment) on pre-term delivery with an adjusted odds ratio of 2.2 (95\% CI 1.2-4.2). BRACKEN et al. [9] studied 873 pregnant females with a history of asthma (of whom 778 had no physician diagnosis, only asthma symptoms) and showed increased odds of pre-term delivery with the use of OCS (adjusted OR 1.11, 95\% CI 1.03-1.18). This particular study was excluded from our meta-analysis since the asthma cohort may have contained non-asthmatic subjects. PERLOW et al. [14] compared 31 steroid-dependent asthmatics to 50 non-steroiddependent asthmatics and found a significantly increased risk of pre-term delivery and low birth weight in the group dependent on OCS.

Since OCS are most commonly used over a short-term to treat exacerbations (which the present meta-analysis shows increases the risk of low birth weight), it would seem that some or even most of the risk of prematurity associated with

TABLE 5 Perinatal outcomes for all sub-groups

\begin{tabular}{|c|c|c|c|}
\hline Outcome & Severity & Exacerbation & OCS \\
\hline Pre-term delivery & $1.06(0.97-1.17)$ & $1.54(0.89-2.69)$ & $1.51(1.15-1.98)^{*}$ \\
\hline Low birth weight & $1.15(1.05-1.26)^{*}$ & $3.02(1.87-4.89)^{\star}$ & $1.41(1.04-1.93)^{\star}$ \\
\hline Small for gestational age & $1.16(1.01-1.33)^{*}$ & $0.78(0.25-2.48)$ & $0.81(0.48-1.34)$ \\
\hline
\end{tabular}

Data are presented as relative risk $(95 \% \mathrm{Cl})$. OCS: oral corticosteroids. *: $p<0.05$ 
OCS may be related to their being a marker for asthma exacerbations. One study did report an association of OCS with prematurity after adjusting for exacerbations and FEV1. Thus a direct effect of OCS cannot be excluded, but it will probably require studies in pregnant patients without asthma to define such a direct effect without confounding by asthma exacerbations.

Aside from OCS, other asthma medications could potentially increase the risks of prematurity or intrauterine growth restriction. When specific medication use was examined there were an insufficient number of articles to include in this metaanalysis. However, the existing data do not suggest that asthma medications, including $\beta$-agonists, inhaled corticosteroids or theophylline contribute to the increased risk of preterm delivery, low birth weight or small for gestational age in the pregnancies of asthmatic females. Further studies are needed to address the safety of these medications during pregnancy.

Our results specifically show that pregnant asthmatics with moderate-to-severe persistent asthma have an increased risk of low birth weight and small for gestational age infants relative to pregnant asthmatics with mild asthma. This is consistent with several prior observations suggesting that pregnant females with lower FEV1 or severe asthma have an increased risk of adverse perinatal outcomes [40] which include small for gestational age infants [15, 57, 92]. DOMBROWSKI et al. [13] adjusted for potential confounders such as smoking, race and socioeconomic status and found that there remained an increased risk of small for gestational age in moderate-to-severe asthmatics. We were unable to separate which of the moderateto-severe asthmatics had sub-optimally controlled asthma. Increased asthma severity may lead to an increased risk of asthma exacerbations as well as more difficult to control chronic asthma, with potential chronic hypoxia. Chronic hypoxia associated with high-altitude pregnancy has been associated with an increased risk of intrauterine growth restriction [93].

It can be hypothesised that better control of asthma during pregnancy will lead to a reduction in asthma exacerbations and thus fewer adverse perinatal outcomes. In support of this, a previous meta-analysis found that active asthma management (defined as investigators of a study being involved in the management and treatment of enrolled subjects with asthma) might be effective in reducing the occurrence of pre-term labour and pre-term delivery [5]. This observation may be explained by active asthma management reducing exacerbations, or courses of OCS, both of which have been implicated in some studies as contributing to the risk of pre-term delivery [19].

Limitations of this meta-analysis include inadequate power based on still-limited sample sizes of studies, differences in definitions between studies of severity and exacerbations, and the inability to control for potential confounding variables. Potential confounders such as socioeconomic status, ethnicity, and smoking history may have explained some of the observed heterogeneity. However, this information was not included in most studies.

There are significant clinical implications of this study. Because females with moderate-to-severe asthma or exacerbations of asthma during pregnancy were at a higher risk of having a premature, low birth weight and/or small for gestational age infant, our results provide a rationale for making the control of asthma a priority in the management of asthma during pregnancy. With adequate control of asthma, there will be a reduction in exacerbations and need for systemic corticosteroids, as well as maternal and fetal hypoxia, which could lead to improvements for the neonate. As a result this could improve outcomes including prematurity and intrauterine growth restriction. Current guidelines recommend that the goal of treatment for the pregnant asthma patient is to provide optimal therapy to maintain control of asthma for maternal health and quality of life. As in the non-pregnant asthmatic, this includes minimising symptoms, exacerbations, limitations in activities and need for rescue medications [94].

In conclusion, the current meta-analysis indicates that those pregnant asthmatics with asthma exacerbations, need for OCS and moderate-to-severe asthma are at an increased risk of preterm delivery, low birth weight and small for gestational age infants. We consider this analysis to have important implications because it suggests that optimal disease control may reduce these adverse perinatal outcomes. Further studies will be necessary to show convincingly that well-controlled asthma is not associated with adverse perinatal outcomes.

\section{STATEMENT OF INTEREST}

Conflict of interest information can be found alongside the online version of this article at www.erj.ersjournals.com

\section{ACKNOWLEDGEMENTS}

We would like to thank Wang Gang (Centre for Asthma and Respiratory Diseases, University of Newcastle and Hunter Medical Research Institute, Newcastle, NSW, Australia) for his assistance.

\section{REFERENCES}

1 Kurinczuk JJ, Parsons DE, Dawes V, et al. The relationship between asthma and smoking during pregnancy. Women Health 1999; 29: 31-47.

2 Kwon HL, Belanger K, Bracken MB. Asthma prevalence among pregnant and childbearing-aged women in the United States: estimates from national health surveys. Ann Epidemiol 2003; 13: 317-324.

3 Clark P, Crawford H, Sims JL, et al. Memorial resolution on the death of William Shainline Middleton, MD. Wis Med J 1976; 75: 28-29.

4 Murphy VE, Gibson PG, Smith R, et al. Asthma during pregnancy: mechanisms and treatment implications. Eur Respir J 2005; 25: 731-750.

5 Murphy V, Namazy J, Powell H, et al. A meta-analysis of adverse perinatal outcomes in women with asthma. Br J Obstet Gynaecol 2011; 118: 1314-1323.

6 Stenius-Aarniala BS, Hedman J, Teramo KA. Acute asthma during pregnancy. Thorax 1996; 51: 411-414.

7 Murphy VE, Gibson P, Talbot PI, et al. Severe asthma exacerbations during pregnancy. Obstet Gynecol 2005; 106: 1046-1054.

8 Rudra CB, Williams MA, Frederick IO, et al. Maternal asthma and risk of preeclampsia: a case-control study. J Reprod Med 2006; 51: 94-100.

9 Bracken MB, Triche EW, Belanger $\mathrm{K}$, et al. Asthma symptoms, severity, and drug therapy: a prospective study of effects on 2205 pregnancies. Obstet Gynecol 2003; 102: 739-752.

10 Olesen C, Thrane N, Nielsen GL, et al. A population-based prescription study of asthma drugs during pregnancy: changing 
the intensity of asthma therapy and perinatal outcomes. Respiration 2001; 68: 256-261.

11 Alexander S, Dodds L, Armson BA. Perinatal outcomes in women with asthma during pregnancy. Obstet Gynecol 1998; 92: 435-440.

12 Jana N, Vasishta K, Saha SC, et al. Effect of bronchial asthma on the course of pregnancy, labour and perinatal outcome. J Obstet Gynaecol 1995; 21: 227-232.

13 Dombrowski MP, Schatz M, Wise $\mathrm{R}$, et al. Asthma during pregnancy. Obstet Gynecol 2004; 103: 5-12.

14 Perlow JH, Montgomery D, Morgan MA, et al. Severity of asthma and perinatal outcome. Am J Obstet Gynecol 1992; 167: 963-967.

15 Schatz M, Zeiger RS, Hoffman CP. Intrauterine growth is related to gestational pulmonary function in pregnant asthmatic women. Kaiser-Permanente Asthma and Pregnancy Study Group. Chest 1990; 98: 389-392.

16 Greenberger PA, Patterson R. The outcome of pregnancy complicated by severe asthma. Allergy Proc 1988; 9: 539-543.

17 Schatz M, Zeiger RS, Hoffman CP, et al. Perinatal outcomes in the pregnancies of asthmatic women: a prospective controlled analysis. Am J Respir Crit Care Med 1995; 151: 1170-1174.

18 Fitzsimons R, Greenberger PA, Patterson R. Outcome of pregnancy in women requiring corticosteroids for severe asthma. J Allergy Clin Immunol 1986; 78: 349-353.

19 Murphy VE, Clifton VL, Gibson PG. Asthma exacerbations during pregnancy: incidence and association with adverse pregnancy outcomes. Thorax 2006; 61: 169-176.

20 Schatz M, Dombrowski MP, Wise R, et al. The relationship of asthma medication use to perinatal outcomes. J Allergy Clin Immunol 2004; 113: 1040-1045.

21 Kallen B, Otterblad Olausson P. Use of anti-asthmatic drugs during pregnancy. 2. Infant characteristics excluding congenital malformations. Eur J Clin Pharmacol 2007; 63: 375-381.

22 Firoozi F, Lemiere C, Ducharme FM, et al. Effect of maternal moderate to severe asthma on perinatal outcomes. Respir Med 2010; 104: 1278-1287.

23 Firoozi F, Lemiere C, Beauchesne MF, et al. Development and validation of database indexes of asthma severity and control. Thorax 2007; 62: 581-587.

24 Blais L, Beauchesne MF, Rey E, et al. Use of inhaled corticosteroids during the first trimester of pregnancy and the risk of congenital malformations among women with asthma. Thorax 2007; 62: 320-328.

25 Ehrenthal DB, Jurkovitz C, Hoffman M, et al. A population study of the contribution of medical comorbidity to the risk of prematurity in blacks. Am J Obstet Gynecol 2007; 197: 409.

26 Fell DB, Dodds L, Joseph KS, et al. Risk factors for hyperemesis gravidarum requiring hospital admission during pregnancy. Obstet Gynecol 2006; 107: 277-284.

27 Sheiner E, Mazor M, Levy A, et al. Pregnancy outcome of asthmatic patients: a population-based study. J Matern Fetal Neonatal Med 2005; 18: 237-240.

28 Acs N, Puho E, Banhidy F, et al. Association between bronchial asthma in pregnancy and shorter gestational age in a populationbased study. J Matern Fetal Neonatal Med 2005; 18: 107-112.

29 Beckmann CA. The effects of asthma on pregnancy and perinatal outcomes. J Asthma 2003; 40: 171-180.

30 Littner Y, Mandel D, Sheffer-Mimouni G, et al. Nucleated red blood cells in infants of mothers with asthma. Am J Obstet Gynecol 2003; 188: 409-412.

31 Liu S, Wen SW, Demissie K, et al. Maternal asthma and pregnancy outcomes: a retrospective cohort study. Am J Obstet Gynecol 2001; 184: 90-96.

32 Demissie K, Breckenridge MB, Rhoads GG. Infant and maternal outcomes in the pregnancies of asthmatic women. Am J Respir Crit Care Med 1998; 158: 1091-1095.

33 Demissie K, Marcella SW, Breckenridge MB, et al. Maternal asthma and transient tachypnea of the newborn. Pediatrics 1998; 102: 84-90.
34 Lehrer S, Stone J, Lapinski R, et al. Association between pregnancy-induced hypertension and asthma during pregnancy. Am J Obstet Gynecol 1993; 168: 1463-1466.

35 Getahun D, Ananth CV, Oyelese Y, et al. Acute and chronic respiratory diseases in pregnancy: associations with spontaneous premature rupture of membranes. J Matern Fetal Neonatal Med 2007; 20: 669-675.

36 Getahun D, Ananth CV, Peltier MR, et al. Acute and chronic respiratory diseases in pregnancy: associations with placental abruption. Am J Obstet Gynecol 2006; 195: 1180-1184.

37 Mabie W, Barton J, Wasserstrum N, et al. Clinical observations on asthma in pregnancy. J Matern Fetal Med 1992; 1: 464-466.

38 Syed RZ, Zubairi AB, Zafar MA, et al. Perinatal outcomes in pregnancy with asthma. J Pak Med Assoc 2008; 58: 525-527.

39 Karimi M, Davar R, Mirzaei M, et al. Pregnancy outcomes in asthmatic women. Iran J Allergy Asthma Immunol 2008; 7: 105-106.

40 Carroll KN, Gebretsadik T, Griffin MR, et al. Maternal asthma and maternal smoking are associated with increased risk of bronchiolitis during infancy. Pediatrics 2007; 119: 1104-1112.

41 Snyder RD, Snyder D. Corticosteroids for asthma during pregnancy. Ann Allergy 1978; 41: 340-341.

42 Breton MC, Beauchesne MF, Lemiere C, et al. Risk of perinatal mortality associated with asthma during pregnancy. Thorax 2009; 64: 101-106.

43 Breton M, Beauchesne MF, Lemiere C, et al. Risk of perinatal mortality associated with asthma durng pregnancy: 2-stage sampling cohort study. Ann Allergy Asthma Immunol 2010; 105: 211-217.

44 Aly H, Nada A, Ahmad T, et al. Maternal asthma, race and low birth weight deliveries. Early Hum Dev 2011; 87: 457-460.

45 Almeida ML, Santana PA, Guimaraes AM, et al. Asthma and pregnancy: repercussions for neonates. J Bras Pneumol 2010; 36: 293-300.

46 Macmullen NJ, Shen JJ, Tymkow C. Adverse maternal outcomes in women with asthma versus women without asthma. Appl Nurs Res 2010; 23: e9-e13.

47 Blais L, Kettani FZ, Elfthouh N, et al. Effect of maternal asthma on the risk of specific congenital malformations: a population-based cohort study. Birth Defects Res A Clin Mol Teratol 2010; 88: 216-222.

48 Clifton VL, Engel P, Smith R, et al. Maternal and neonatal outcomes of pregnancies complicated by asthma in an Australian population. Aust N Z J Obstet Gynaecol 2009; 49: 619-626.

49 Mihrshahi S, Belousova E, Marks GB, et al. Pregnancy and birth outcomes in families with asthma. J Asthma 2003; 40: 181-187.

50 Greenberger PA, Patterson R. Beclomethasone diproprionate for severe asthma during pregnancy. Ann Intern Med 1983; 98: 478-480.

51 Hendler I, Schatz M, Momirova V, et al. Association of obesity with pulmonary and nonpulmonary complications of pregnancy in asthmatic women. Obstet Gynecol 2006; 108: 77-82.

52 Savilahti E, Siltanen M, Pekkanen J, et al. Mothers of very low birth weight infants have less atopy than mothers of full-term infants. Clin Exp Allergy 2004; 34: 1851-1854.

53 Wendel PJ, Ramin SM, Barnett-Hamm C, et al. Asthma treatment in pregnancy: a randomized controlled study. Am J Obstet Gynecol 1996; 175: 150-154.

54 Blais L, Beauchesne MF, Lemiere C, et al. High doses of inhaled corticosteroids during the first trimester of pregnancy and congenital malformations. J Allergy Clin Immunol 2009; 124: 1229-1234.

55 Kallen B, Otterblad Olausson P. Use of anti-asthmatic drugs during pregnancy. 3. Congenital malformations in the infants. Eur J Clin Pharmacol 2007; 63: 383-388.

56 Macmullen NJ, Tymkow C, Shen JJ. Adverse maternal outcomes in women with asthma: differences by race. MCN Am J Matern Child Nurs 2006; 31: 263-268. 
57 Norjavaara E, de Verdier MG. Normal pregnancy outcomes in a population-based study including 2,968 pregnant women exposed to budesonide. J Allergy Clin Immunol 2003; 111: 736-742.

58 Wen SW, Demissie K, Liu S. Adverse outcomes in pregnancies of asthmatic women: results from a Canadian population. Ann Epidemiol 2001; 11: 7-12.

59 Reece EA, Moya F, Yazigi R, et al. Persistent pulmonary hypertension: assessment of perinatal risk factors. Obstet Gynecol 1987; 70: 696-700.

60 Dombrowski MP, Bottoms SF, Boike GM, et al. Incidence of preeclampsia among asthmatic patients lower with theophylline. Am J Obstet Gynecol 1986; 155: 265-267.

61 Clark JM, Hulme E, Devendrakumar V, et al. Effect of maternal asthma on birthweight and neonatal outcome in a British innercity population. Paediatr Perinat Epidemiol 2007; 21: 154-162.

62 Lao TT, Huengsburg M. Labour and delivery in mothers with asthma. Eur J Obstet Gynecol Reprod Biol 1990; 35: 183-190.

63 Eltonsy S, Forget A, Blais L. $\beta$-agonists use during pregnancy and the risk of congenital malformations. Birth Defects Research 2011; 91: 937-947.

64 Breton MC, Beauchesne MF, Lemiere C, et al. Risk of perinatal mortality associated with inhaled corticosteroid use for the treatment of asthma during pregnancy. J Allergy Clin Immunol 2010; 126: 772-777.

65 Martel MJ, Beauchesne MF, Malo JL, et al. Maternal asthma, its control and severity in pregnancy, and the incidence of atopic dermatitis and allergic rhinitis in the offspring. J Pediatr 2009; 155: 707-713.

66 Schatz M, Dombrowski MP, Wise R, et al. Spirometry is related to perinatal outcomes in pregnant women with asthma. Am J Obstet Gynecol 2006; 194: 120-126.

67 Schatz M, Zeiger R, Harden KM, et al. The safety of inhaled $\beta$ agonist bronchodilators during pregnancy. J Allergy Clin Immunol 1988; 82: 686-695.

68 Schatz M, Dombrowski MP, Wise R, et al. The relationship of asthma-specific quality of life during pregnancy to subsequent asthma and perinatal morbidity. J Asthma 2010; 47: 46-50.

69 Stenius-Aarniala B, Piirila P, Teramo K. Asthma and pregnancy: a prospective study of 198 pregnancies. Thorax 1988; 43: 12-18.

70 Stenius-Aarniala B, Riikonen S, Teramo K. Slow-release theophylline in pregnant asthmatics. Chest 1995; 107: 642-647.

71 Minerbi-Codish I, Fraser D, Avnun L, et al. Influence of asthma in pregnancy on labor and the newborn. Respiration 1998; 65: 130-135.

72 Moldenhauer JS, Lai Y, Schatz M, et al. Influence of maternal asthma and asthma severity on newborn morphometry. J Asthma 2010; 47: 145-149.

73 Sarkar M, Koren G, Kalra S, et al. Montelukast use during pregnancy: a multicentre, prospective, comparative study of infant outcomes. Eur J Clin Pharmacol 2009; 65: 1259-1264.

74 Silverman M, Sheffer A, Diaz PV, et al. Outcome of pregnancy in a randomized controlled study of patients with asthma exposed to budesonide. Ann Allergy Asthma Immunol 2005; 95: 566-570.

75 Kallen B, Otterblad Olausson P. Use of anti-asthmatic drugs during pregnancy. 1. Maternal characteristics, pregnancy and delivery complications. Eur J Clin Pharmacol 2007; 63: 363-373.

76 Triche EW, Saftlas AF, Belanger K, et al. Association of asthma diagnosis, severity, symptoms, and treatment with risk of preeclampsia. Obstet Gynecol 2004; 104: 585-593.
77 Doucette JT, Bracken MB. Possible role of asthma in the risk of preterm labor and delivery. Epidemiology 1993; 4: 143-150.

78 Schatz M, Zeiger RS, Harden K, et al. The safety of asthma and allergy medications during pregnancy. J Allergy Clin Immunol 1997; 100: 301-306.

79 Bakhireva LN, Schatz M, Jones KL, et al. Asthma control during pregnancy and the risk of preterm delivery or impaired fetal growth. Ann Allergy Asthma Immunol 2008; 101: 137-143.

80 Twaites BR, Wilton LV, Shakir SAW. Safety of zafirlukast: results of a postmarketing surveillance study on 7976 patients in England. Drug Saf 2007; 30: 419-429.

81 Bakhireva LN, Jones KL, Schatz M, et al. Asthma medication use in pregnancy and fetal growth. J Allergy Clin Immunol 2005; 116: 503-509.

82 Dombrowski MP, Brown CL, Berry SM. Preliminary experience with triamcinolone acetonide during pregnancy. J Matern Fetal Med 1996; 5: 310-313.

83 Bakhireva LN, Jones KL, Schatz M, et al. Safety of leukotriene receptor antagonists in pregnancy. J Allergy Clin Immunol 2007; 119: 618-625.

84 Schatz M, Patterson R, Zeitz S, et al. Corticosteroid therapy for the pregnant asthmatic patient. JAMA 1975; 233: 804-807.

85 Murphy VE, Fittock RJ, Zarzycki PK, et al. Metabolism of synthetic steroids by the human placenta. Placenta 2007; 28: 39-46.

86 Namazy J, Schatz M, Long L, et al. Use of inhaled steroids by pregnant asthmatic women does not reduce intrauterine growth J Allergy Clin Immunol 2004; 113: 427-432.

87 Clifton VL, Rennie N, Murphy VE. Effect of inhaled glucocorticoid treatment on placental 11ß-hydroxysteroid dehydrogenase type 2 activity and neonatal birthweight in pregnancies complicated by asthma. Aust N Z J Obstet Gynaecol 2006; 46: 136-140.

88 Dombrowski MP, Schatz M, Wise R, et al. Randomized trial of inhaled beclomethasone dipropionate versus theophylline for moderate asthma during pregnancy. Am J Obstet Gynecol 2004; 190: 737-744

89 Wells GA, Shea B, O'Connell D, et al. The Newcastle-Ottawa Scale (NOS) for assessing the quality of non-randomized studies in meta-analyses. www.ohri.ca/programs/clinical_epidemiology/ oxford.asp. Date last accessed: March 29, 2013.

90 Stroup D, Berlin J, Morton S, et al. Meta-analysis of observational studies in epidemiology: a proposal for reporting. Meta-analysis of Observational Studies in Epidemiology (MOOSE) group. JAMA 2000; 283: 2008-2012.

91 Enriquez R, Griffin MR, Carroll $\mathrm{KN}$, et al. Effect of maternal asthma and asthma control on pregnancy and perinatal outcomes. J Allergy Clin Immunol 2007; 120: 625-630.

92 Sims CD, Chamberlain GV, de Swiet M. Lung function tests in bronchial asthma during and after pregnancy. Br J Obstet Gynaecol 1976; 83: 434-437.

93 Keyes LE, Armaza JF, Niermeyer S, et al. Intrauterine growth restriction, preeclampsia, and intrauterine mortality at high altitude in Bolivia. Pediatr Res 2003; 54: 20-25.

94 Busse WW. NAEPP expert panel report. Managing asthma during pregnancy: recommendations for pharmacologic treatment - 2004 update. J Allergy Clin Immunol 2005; 115: 34-46. 